\title{
Avaliação do efeito do undecilato de boldenona no desenvolvimento de testículo e ovário em potros
}

Hortência Campos Mazzo ${ }^{[a]}$, Murillo Ormieres ${ }^{[a]}$, Gabriela do Vale Pombo ${ }^{[a]}$, Yasmin de Sales Pereira ${ }^{[a]}$, Nicolas Ventura Duarte ${ }^{[a]}$, Katia Feltre ${ }^{[a]}$, Baity Boock Lea ${ }^{[b]}$, Marcelo Augusto Ferreira ${ }^{[b]}$, Paula Bandiera Leite ${ }^{[b]}$, Bruna Cerruti de Godoi ${ }^{[b]}$, Sandra Fernandez ${ }^{[b]}$,Alexandre Augusto de Oliveira Gobesso ${ }^{[a]}$

\footnotetext{
[a] Universidade de São Paulo (USP), Pirassununga, SP, Brasil
}

[b] Ceva Saúde Animal, Paulínia, SP, Brasil

*Autor correspondente

e-mail: htncia@hotmail.com

\section{Resumo}

O desenvolvimento dos órgãos reprodutivos, especialmente na fase da puberdade, é um bom indicador de eficiência reprodutiva em potros. A biometria testicular tem como principais finalidades diagnosticar alterações, assim como auxiliar na predição do potencial reprodutivo bem como da produção espermática diária. A mensuração ovariana é descrita como um parâmetro de avaliação de maturidade. Esteroides anabólicos androgênicos são compostos naturais e/ou agentes sintéticos derivados da testosterona ou modificados, que atuam promovendo aumento das atividades anabólicas e androgênicas, sendo maiores os efeitos anabólicos quando comparadas aos androgênicos. 0 undecilenato de boldenona é um agente anabólico de longa duração que atua nos cavalos aumentando a retenção de nitrogênio e a síntese de proteínas, estimulando o crescimento da musculatura e promovendo consequente aumento do desempenho esportivo e crescimento acelerado. Autores relatam dentre os efeitos indesejáveis do uso da boldenona, a diminuição testicular em várias espécies, bem como efeitos na atividade ovariana. Desta forma, o estudo foi conduzido com o objetivo de avaliar o efeito da aplicação de undecilenato de boldenona (Equifort), no desenvolvimento de testículo e ovário em potros na puberdade. Foram utilizados 11 potros (cinco machos mestiços e seis fêmeas mestiças com Brasileiro de Hipismo), \pm 17 meses e peso corporal médio de 355,17 $\pm 26,63 \mathrm{~kg}$ e de $411,42 \pm 29,49 \mathrm{~kg}$, respectivamente. 0 consumo diário individual adotado foi de $2,0 \%$ do peso corporal (PC) em matéria seca. Os animais ficaram em piquetes sem acesso ao capim, recebendo dieta com relação 50:50 [50\% concentrado farelado e 50\% feno de Tifton 85 (Cynodon spp.)], água e suplemento mineral ad libitum. Os animais foram divididos em 2 grupos experimentais: GI- Grupo Controle, seis animais (três machos e três fêmeas); GII- Grupo Tratado, cinco animais (dois machos e três fêmeas). No início do experimento (D0), o GII foi submetido à administração de undecilenato de boldenona (Equifort) 
na posologia recomendada pelo fabricante $(0,25 \mathrm{~mL} / 50 \mathrm{~kg}$ de PC), via intramuscular profunda. 0 período experimental foi composto por 87 dias. Nos dias D0, D14, D28, D44, D59, D74 e D85 foram realizados exames ultrassonográficos onde foram mensurados o comprimento e largura dos testículos e o comprimento na vertical (largura) e na horizontal (altura) do ovário para acompanhar o crescimento. A análise estatística da mensuração testicular não evidenciou qualquer diferença entre os grupos com relação ao comprimento testicular direito (GI 43,13 $\mathrm{mm} \pm 4,70$; GII 41,97 $\mathrm{mm} \pm 4,51$ ) e esquerdo (GI 45,89 $\mathrm{mm} \pm 5,51$; GII $44,73 \mathrm{~mm}$ $\pm 4,12$ ) e largura do testículo direito (GI $24,78 \mathrm{~mm} \pm 3,03$; GII 26,27 $\mathrm{mm} \pm 5,27$ ) e esquerdo (GI $24,82 \mathrm{~mm}$ $\pm 4,22$; GII $27,13 \mathrm{~mm} \pm 3,08)$ dos potros $(\mathrm{P} \geq 0,05)$. No entanto, ao avaliar a largura do testículo esquerdo, quando comparado ao D0 (GI 26,7 $\mathrm{mm} \pm 3,3$; GII 19,4 $\mathrm{mm} \pm 1,4$ ), D28 (GI 19,7 $\mathrm{mm} \pm 4,8$; GII 21,7 $\mathrm{mm} \pm 7,4$ ) apresentou um aumento em ambos os grupos $(\mathrm{P} \geq 0,05)$. Da mesma forma, no que diz respeito à média da mensuração ovariana, não foram encontradas diferenças na largura do ovário direito (GI 29,15 mm $\pm 6,24$; GII 27,55 $\mathrm{mm} \pm 4,17$ ) e esquerdo (GI 30,34 $\mathrm{mm} \pm 6,22$; GII $28,54 \mathrm{~mm} \pm 3,21$ ) e altura do ovário direito (GI $23,5 \mathrm{~mm} \pm 5,63$; GII $21,20 \mathrm{~mm} \pm 1,53$ ) e esquerdo (GI 23,47 $\mathrm{mm} \pm 2,80$; GII 21,50 $\mathrm{mm} \pm 3,17$ ) das potras $(\mathrm{P} \geq 0,05)$. No entanto, ao avaliar a altura do ovário esquerdo, observa-se que em D28 (GI 23,4 mm $\pm 7,1$; GII 27,6 $\mathrm{mm} \pm 5,1)$ esta apresentou um aumento $(\mathrm{P} \geq 0,05)$ quando comparado ao mesmo parâmetro de D0 (GI 21,0mm $\pm 4,2$; GII 21,3mm $\pm 0,7$ ) em ambos os grupos. Tais alterações já eram esperadas, uma vez que os potros se encontram em pleno desenvolvimento reprodutivo. A observação do mesmo resultado em ambos os tratamentos evidencia que não há qualquer correlação com o uso do produto. Assim, conclui-se que o uso do undecilenato de boldenona (Equifort) não provocou modificações no que diz respeito ao tamanho de testículo e ovário dos potros.

Palavras-chave: Androgênicos. Equinos. Gônada. 